\title{
Incidence of and Risk Factors for Missing Events Due to Wandering in Community-dwelling Older People with Dementia and Mild Cognitive Impairment
}

seungwon Jeong ( $\nabla$ k-jeong@niimi-u.ac.jp)

Niimi Koritsu Daigaku https://orcid.org/0000-0003-2919-7508

Takao Suzuki

J F Oberlin University: Obirin Daigaku

Kiyoko Miura

National Center for Geriatrics and Gerontology Research Institute Department of Regenerative Medicine: Kokuritsu Choju Iryo Kenkyu Center Kenkyujo Saisei Saiken Igaku Kenkyubu

Takashi Sakurai

National Center for Geriatrics and Gerontology Research Institute Department of Regenerative Medicine: Kokuritsu Choju Iryo Kenkyu Center Kenkyujo Saisei Saiken Igaku Kenkyubu

\section{Research Article}

Keywords: dementia-related wandering, the risk factors for the incidence of wandering, the incidence and recurrence rate of missing events, dementia , mild cognitive impairment $(\mathrm{MCl})$, prospective cohort study

Posted Date: July 1st, 2021

DOI: https://doi.org/10.21203/rs.3.rs-673163/v1

License: @ (i) This work is licensed under a Creative Commons Attribution 4.0 International License. Read Full License 


\section{Abstract}

Background

The burden of missing incidents is not only on the person with dementia, but also on their family, neighbors, and community. The extent to which dementiarelated wandering and missing incidents occur in the community has not been evaluated thoroughly in the published literature. Therefore, we evaluated the incidence of and risk factors for missing events due to wandering.

\section{Methods}

We conducted a non-randomized prospective one-year follow-up cohort study based on symptom registration with missing events due to wandering as the endpoint. In the first consultation, 374 patients with dementia or mild cognitive impairment (MCl) and their caregivers who visited the National Center for Geriatrics and Gerontology in Japan were included. The incidence and recurrence rate of missing events were calculated. Participants were divided into (those with) dementia and (those with) $\mathrm{MCl}$. Patients' basic and medical information was documented at baseline and after one year of follow-up. Furthermore, analysis of variance and logistic regression analysis were performed to clarify the risk factors associated with the missing event.

\section{Results}

Among the 236 patients with dementia enrolled, 65 (27.5\%) had a previous missing event at baseline, and 28 had a missing event during the one-year followup period (recurrence rate of $43 \cdot 1 \%$ ). Of the 171 who did not have a previous missing event at baseline, 23 had a missing event during the one-year follow-up period (incidence rate of 13.5\%). The scores of Mini-Mental State Examination (MMSE), Dementia Behavior Disturbance Scale (DBD), and Alzheimer's Disease Assessment Scale (ADAS) were statistically significant as the risk factors for the incidence of wandering leading to a missing event ( $<<0 \cdot 05)$.

\section{Conclusions}

Prevention of missing event due to wandering requires focused attention on changes in the MMSE, DBD, ADAS scores, and the development of a social environment to support family caregivers.

\section{Background}

Populations are aging globally, and the number of older adults with dementia is increasing. About 50 million people worldwide have dementia, with nearly 10 million new cases being diagnosed every year [1].

Wandering in the context of dementia has been seen as a syndrome of frequent, repetitive, seemingly aimless, typically temporally, and spatially-disoriented ambulation [2, 3]. Eventually, $60 \%-80 \%$ of people with dementia will wander [4, 5]. Wandering due to dementia has sometimes led to fatal accidents [6, 7].

Of particular note is that many patients with dementia live with their families in their homes in the community. Therefore, when wandering or missing incidents occur in the community, the burden is not only on the person with dementia, but also on their family, neighbors, and community [8]. However, not enough studies have thoroughly examined the extent to which dementia-related wandering and missing incidents occur in the community.

Previous studies have determined some risk factors of wandering to impair certain brain functions, especially spatial memory, visuospatial processes or executive functions [9], and severity of dementia $[10,11]$. However, it is still unclear how dementia and a decline in cognitive function are linked to missing incidents.

Therefore, we conducted a prospective cohort study based on symptom registration with missing events due to wandering as the endpoint. We then analyzed which factors could predict the incidence of missing events more clearly.

\section{Methods}

\section{Study design}

Setting: Non-randomized prospective cohort study

\section{Study participants}

Of the patients with dementia and mild cognitive impairment $(\mathrm{MCl})$ who visited the Center for Comprehensive Care and Research on Memory Disorders at the National Center for Geriatrics and Gerontology for their first consultation between April 2017 and March 2018, we investigated all those who (1) could understand the Japanese language, (2) were accompanied by a caregiver, and (3) provided consent to participate in the study. Consent was also taken from the caregivers of the participating patients.

\section{Consent to participate}

in the study was received from 490 pairs of patients and their caregivers, from which 54 pairs were excluded for the lack of either dementia or $\mathrm{MCl}$ and one for living in a nursing home. Thus, 374 pairs participated in the study (Fig. 1). Of the 60 participants who dropped out, we could not determine if there were missing events in 31 who could not be traced (refused tracing), 12 who died, and 17 who were admitted to a nursing home. 


\section{Definition and assessment of wandering and missing events}

The word "wandering" is widely used to cover a diversity of actions and is often seen as a type of disturbed behavior [12]. Although "a syndrome of dementiarelated locomotion behavior" was proposed as the definition of wandering in 2007 [3], there is still a lack of consensus. In recent years, this term has often been confounded with "missing" and "getting lost."

In the present study, we primarily use the term "missing" and limited our investigations to dementia-related missing events due to wandering. Missing was defined as being (1) related to dementia, (2) associated with movement, and (3) strongly related to wandering behavior, and the focus was placed on being "missing" from the viewpoint of the caregiver.

We created the following questionnaires for caregivers using the Algase wandering scale and conceptual domain [13], the wandering questionnaire by Houston et al. [14], the Awata group episodes [6], and the missing incidents conceptual model by Rowe et al. [15] as references. If any of the following five conditions were true for the patient, a missing event due to wandering was recorded: (1) The patient was outside and did not know where he/she was; (2) the patient went out and did not return within the expected time; (3) the patient went out at night; (4) the patient was agitated and went out; (5) the patient had been lost at least once.

\section{Variables used in the analysis}

Patients and their family members were given questionnaires and interviews at the time of registration. Data was collected on factors, such as basic attributes, medical information, and a sense of family burden. To test the reliability of a self-reported questionnaire, a side-by-side comparison was made of the questionnaire responses and interview responses, giving $81.4 \%$ consistency. A follow-up study was performed a year after registration, and mail surveys were administered to determine the occurrence and frequency of missing events during the year. Of those surveyed in the follow-up, 53 randomly selected participants were interviewed for a test of reliability in a self-reported questionnaire, with an $84.9 \%$ consistency. Generally, high reliability was observed for questionnaire responses.

The following information was obtained at baseline:

1. Diagnosis of dementia or $\mathrm{MCl}$.

2. Basic information about patients: sex, age, years of education, living alone or with someone else, and financial difficulties, if any.

3. Medical information about patients: body mass index (BMI), scores for Barthel index (1-100), Mini-Mental State Examination (MMSE; 0-30), Dementia Behavior Disturbance Scale (DBD; 0-112), Alzheimer's Disease Assessment Scale (ADAS; 0-70), Raven's Colored Progressive Matrices (RCPM; 0-36), Frontal Assessment Battery (FAB; $0-18)$, geriatric syndrome (0-24), vitality index (0-10), Geriatric Depression Scale (GDS; 1-15), and anti-dementia medication (yes or no).

4. Lifestyle choices of patients: alcohol consumption, smoking, sleep disorders, absence of exercise.

5. Information about family caregivers: sex, age, years of education, employment (yes or no), providing care every day (yes or no), availability of other caregivers (yes or no), nursing care experience for dementia (yes or no), participation in a course on dementia (yes or no), health problems, physical pain (yes or no), sleep condition, appetite, GDS (1-15), the Japanese version of the Zarit caregiver burden interview (J-ZBI) [16] score (0-88) (Table 1).

\section{Statistical analysis}

The incidence rate and recurrence rate of missing events were calculated (Fig. 2). Participants were divided into those with dementia and those with $\mathrm{MCl}$, and patients' basic information and medical information were shown at baseline and after one year of follow-up. Patients were then divided into those who did not go missing (no missing event), those who went missing for the first time (incidence), and those who had a recurrent missing event during the year of follow-up (recurrence). Analysis of variance and post-hoc tests were performed to look for differences in the variables at baseline. Univariate and multivariate logistic analyses were performed to find the incidence of missing events during follow-up and related variables. Variables that were statistically significant in the univariate logistic analysis were used as variables in the multivariate logistic analysis.

Multivariate logistic regression analysis was performed to examine the risk factors of incidence and recurrence of missing events during the one-year followup period as the dependent variable and medical and social factors as independent variables. We controlled for the patients' sex, age, years of education, and financial difficulties. Statistical analysis was conducted with SPSS ver.25 (Chicago, IL, USA). A two-sided $p<0.05$ was considered statistically significant.

\section{Ethical Considerations}

This study adhered to the tenets of the Declaration of Helsinki and the ethical standards declared in ethical guidelines for medical research involving human subjects. The Ethics and Conflicts approved the study protocol of the Interest Committee of the National Center for Geriatrics and Gerontology (No. 977-2).

\section{Results}

Missing events and related variables clearly differed between patients with dementia and patients with MCl.

\section{Incidence and recurrence rate of missing events}

Among the 236 patients with dementia, 65 (27.5\%) had a previous missing event at baseline, and 171 (72.5\%) did not. Including both of those with and without a previous missing event at baseline, 51 (21.6\%) had a missing event during the one-year follow-up period.

Page $3 / 11$ 
Of the 65 patients with dementia who had a previous missing event at baseline, 28 had a missing event during the one-year follow-up period (recurrence rate of $43.1 \%$ ). Of the 171 who did not have a previous missing event at baseline, 23 had a missing event during the one-year follow-up period (incidence rate of $13.5 \%$.

Of the 138 patients with $\mathrm{MCl}, 13(9.4 \%)$ had a previous missing event at baseline. During the one-year follow-up period, four $\mathrm{MCl}$ patients had their first missing event (incidence rate of 3.2\%), and three had a recurrent missing event (recurrence rate of 23.1\%) (Fig. 2).

\section{Differences in medical variables between those who did and those who did not have a missing event during the one-year follow-up period}

To further investigate factors related to the incidence and recurrence of missing events, baseline characteristics were tested to determine the differences between those who did and those who did not have a missing event during the one-year follow-up period. Patients with dementia and patients with $\mathrm{MCl}$ were analyzed separately.

Of the 236 patients with dementia, 171 (72.5\%) had Alzheimer's disease, 21 (8.9\%) had dementia with Lewy bodies or Parkinson's disease with dementia, 17 (7.2\%) had vascular dementia, five (2.1\%) had frontotemporal dementia, and 22 (9.3\%) had another form of dementia (Table 1).

In the year of follow-up, the group with no missing events, the incidence group, and the recurrence group did not differ significantly in basic attributes (e.g., sex, age, years of education, living alone or financial difficulty) or lifestyle (e.g., alcohol consumption, smoking, sleep disorder, absence of daily exercise; Table 1).

Regarding medical factors, group differences were seen in MMSE, DBD, ADAS, RCPM, and GDS scores. The mean MMSE score was significantly lower in the recurrence group (16.5) than in the incidence group (18.2) and in the group with no missing events (19.3; $p<0.01)$. The mean DBD score was significantly higher in the recurrence group (26.1) than in the incidence group (19.6) and in the group with no missing events $(15.7 ; p<0.001)$. The mean ADAS score was significantly higher in the recurrence group (23.2) than in the incidence group (18.3) and in the group with no missing events (17.8; $<<0.001)$. The mean RCPM score was significantly lower in the recurrence group (17.6) than in the incidence group (19.4) and in the group with no missing events (21.9; $p<0.001)$. The GDS score differed significantly between the incidence group and the recurrence group $(2.9$ vs. $4.9, p<0.03 ;$ Table 1$)$.

Among caregivers, the ratio of those providing care every day was significantly higher in the recurrence group (92.9\%) than in the incidence group (69.6\%) and in the group with no missing events (74.1\%). The GDS score of caregivers was 5.1 in the recurrence group, 3.6 in the incidence group, and 3.2 in the group with no missing events. The J-ZBI score was significantly higher in the recurrence group (32.6) than in the incidence group (27.4) and in the group with no missing events (20.9; Table 1).

We performed the same tests on patients with $\mathrm{MCl}$ and found that 7 of the 138 (5.1\%) had a missing event during the one-year follow-up period; no significant differences were observed between these seven individuals and those who did not have a missing event. 
Table 1

Differences in the characteristics at baseline and after one-year follow-up

\begin{tabular}{|c|c|c|c|c|c|c|}
\hline & \multirow[t]{2}{*}{ Factor } & \multirow{2}{*}{$\begin{array}{l}\text { Baseline } \\
\text { Total } \\
(n=236)\end{array}$} & \multicolumn{4}{|c|}{ One year follow-up } \\
\hline & & & $\begin{array}{l}\text { none } \\
(n=185)\end{array}$ & $\begin{array}{l}\text { incidence } \\
(n=23)\end{array}$ & $\begin{array}{l}\text { recurrence } \\
(\mathrm{n}=28)\end{array}$ & $P$ \\
\hline \multirow[t]{5}{*}{ Diagnosis } & Alzheimer's disease, n(\%) & $171(72.5)$ & $134(72.4)$ & $12(52.2)$ & 25(89.3) & NA \\
\hline & $\begin{array}{l}\text { Dementia with Lewy bodies or Parkinson's disease with dementia, } \\
\mathrm{n}(\%)\end{array}$ & 21(8.9) & 16(8.6) & $3(13.0)$ & $2(7.1)$ & NA \\
\hline & Vascular dementia, n(\%) & $17(7.2)$ & $13(7.0)$ & $3(13.0)$ & $1(3.6)$ & NA \\
\hline & Frontotemporal dementia, n(\%) & $5(2.1)$ & $3(1.6)$ & $2(8.7)$ & $0(0.0)$ & NA \\
\hline & Others, n(\%) & $22(9.3)$ & 19(10.3) & $3(13.0)$ & $0(0.0)$ & NA \\
\hline \multirow[t]{5}{*}{ Basic attributes } & Sex ${ }^{\dagger}$ Female, $n(\%)$ & $136(58.9)$ & 114(61.6) & $13(56.5)$ & $12(42.9)$ & n.s \\
\hline & Age, mean (SD) & $79.4(7.0)$ & $79.8(7.0)$ & $78.3(7.8)$ & $77.8(5.5)$ & n.s. \\
\hline & Years of education, mean (SD) & $10.6(2.8)$ & $10.6(2.8)$ & $10.5(2.2)$ & $10.7(2.9)$ & n.s. \\
\hline & Living alone ${ }^{\dagger \dagger}, \mathrm{n}(\%)$ & $39(16.5)$ & $33(17.8)$ & $3(13.0)$ & $3(10.7)$ & n.s. \\
\hline & Financial difficulty ${ }^{\dagger \dagger}, \mathrm{n}(\%)$ & 18(7.7) & 13(7.1) & $2(8.7)$ & $3(10.7)$ & n.s. \\
\hline \multirow[t]{11}{*}{ Medical factors } & Body mass index, mean(SD) & $21.9(3.4)$ & $22.0(3.5)$ & $22.4(3.3)$ & $20.8(2.9)$ & n.s. \\
\hline & Barthel Index, mean(SD) & $94.5(11.5)$ & $94.6(11.8)$ & $95.4(10.4)$ & $93.2(10.4)$ & n.s. \\
\hline & Mini-Mental State Examination, mean(SD) & $18.8(4.0)$ & $19.3(3.8) *$ & $18.2(4.3)$ & $16.5(4.2) *$ & 0.01 \\
\hline & Dementia Behavior Disturbance Scale, mean(SD) & 17.3(10.7) & $15.7(9.6) *$ & 19.6(10.4) & $26.1(13.2)$ & $\begin{array}{l}p< \\
0.001\end{array}$ \\
\hline & Alzheimer's Disease Assessment Scale, mean(SD) & $18.5(5.8)$ & $17.8(5.5) *$ & $18.3(5.5) *$ & $23.2(6.3) *$ & $\begin{array}{l}\mathrm{p}< \\
0.001\end{array}$ \\
\hline & Raven's Colored Progressive Matrices, mean(SD) & 21.2(6.6) & $21.9(5.9) *$ & $19.4(7.8)$ & $17.6(8.6)^{*}$ & 0.01 \\
\hline & Frontal Assessment Battery, mean(SD) & $8.4(3.3)$ & $8.7(3.3)$ & 7.6(3.4) & 7.3(3.2) & n.s. \\
\hline & Geriatric syndrome, mean(SD) & $3.6(2.9)$ & $4.6(3.2)$ & $6.3(4.6)$ & $4.3(2.9)$ & n.s. \\
\hline & Vitality index, mean(SD) & $8.6(1.4)$ & $8.6(1.4)$ & $8.6(1.4)$ & $8.3(1.4)$ & n.s. \\
\hline & Geriatric Depression Scale, mean(SD) & $3.6(2.9)$ & $3.5(2.8)$ & $4.9(3.4) *$ & $2.9(2.8) *$ & 0.03 \\
\hline & Taking anti-dementia medication ${ }^{\dagger+}, \mathrm{n}(\%)$ & $49(20.8)$ & $36(19.5)$ & $3(13.0)$ & $10(35.7)$ & n.s. \\
\hline \multirow[t]{4}{*}{ Life style } & Alcohol $^{\dagger}, \mathrm{n}(\%)$ & $68(28.8)$ & $56(30.3)$ & $5(21.7)$ & $7(25.0)$ & n.s. \\
\hline & Smoking $^{\dagger \dagger}, \mathrm{n}(\%)$ & $32(13.6)$ & $24(13.0)$ & $2(8.7)$ & $6(21.4)$ & n.s. \\
\hline & Sleeping disorder ${ }^{\dagger}, \mathrm{n}(\%)$ & $95(40.8)$ & $71(38.8)$ & $14(63.6)$ & 10(35.7) & n.s. \\
\hline & No Exercise ${ }^{\dagger}, \mathrm{n}(\%)$ & 104(44.1) & $76(41.1)$ & $14(60.9)$ & $14(50.0)$ & n.s. \\
\hline \multirow{9}{*}{$\begin{array}{l}\text { Caregiver's } \\
\text { factors }\end{array}$} & Sex ${ }^{\dagger}$ Female, $n(\%)$ & 169(71.6) & 130(70.3) & 17(73.9) & $22(78.6)$ & n.s. \\
\hline & Age, mean(SD) & $62.2(11.9)$ & $62.2(11.8)$ & $63.9(13.8)$ & $60.8(11.4)$ & n.s. \\
\hline & Years of education, mean(SD) & $12.7(2.3)$ & $12.8(2.3)$ & $12.3(2.8)$ & $12(1.8)$ & n.s. \\
\hline & Employed $^{\dagger}, \mathrm{n}(\%)$ & $133(56.4)$ & 108(58.4) & $11(47.8)$ & $14(50.0)$ & n.s. \\
\hline & Providing care every day, n(\%) & $179(75.8)$ & $137(74.1)^{\star}$ & $16(69.6)^{*}$ & $26(92.9)^{*}$ & 0.01 \\
\hline & Availability of other caregivers, $\mathrm{n}(\%)^{\dagger+}$ & $16(6.8)$ & 11(5.9) & $1(4.3)$ & $4(14.3)$ & n.s. \\
\hline & Experience of caregiving for dementia patient, n(\%) & $45(19.1)$ & $35(18.9)$ & $5(21.7)$ & $5(17.9)$ & n.s. \\
\hline & Attended seminar for caregiving to dementia patient, $n(\%)$ & $41(17.4)$ & $33(17.8)$ & $7(30.4)$ & $1(3.6)$ & n.s. \\
\hline & Poor physical health, n(\%) & $46(19.5)$ & $33(17.8)$ & $6(26.1)$ & $7(25.0)$ & n.s. \\
\hline
\end{tabular}

${ }^{\dagger} \chi^{2}$ test ${ }^{\dagger+}{ }^{+\dagger}$ Fisher exact test $\square{ }^{\star}$ post hoc test. n.s.- Not significant, NA - Not applicable, SD - Standard deviation 


\begin{tabular}{|c|c|c|c|c|c|}
\hline Geriatric Depression Scale, mean(SD) & $3.5(2.9)$ & $3.2(2.6) *$ & $3.6(3.2)$ & $5.1(3.5)^{*}$ & 0.01 \\
\hline $\begin{array}{l}\text { Japanese version of the Zarit caregiver burden interview, } \\
\text { mean(SD) }\end{array}$ & $22.9(14.9)$ & $20.9(14.1)$ & $27.4(16.9)$ & $32.6(14.2)$ & $\begin{array}{l}\mathrm{p}< \\
0.001\end{array}$ \\
\hline
\end{tabular}

${ }^{\dagger} \chi^{2}$ test, ${ }^{\dagger \dagger}$ Fisher exact test ${ }^{*}$ post hoc test. n.s.- Not significant, NA - Not applicable, SD - Standard deviation

\section{Risk factors of incidence and recurrence of missing events due to wandering}

Logistic regression analysis was performed to examine the risk factors for the incidence and recurrence of missing events with incidence or recurrence of missing events during the one-year follow-up period as the dependent variable and baseline factors as independent variables (Table 2).

First, a univariate logistic analysis was performed on patients with dementia with medical and caregiver-related factors as independent variables, and all models were adjusted for age. The MMSE, DBD, ADAS, RCPM, and FAB scores and caregivers' GDS and J-ZBI scores significantly affected the ratio of those who had a missing event. Next, a multivariate logistic analysis was performed with variables that were significant in the univariate logistic analysis. Multivariate logistic analysis performed with missing events during the one-year follow-up period as the dependent variable showed significant differences in the MMSE and DBD scores. An analysis was performed separately on the incidence group and the recurrence group. Significant differences remained only for the MMSE score in the incidence group and for the ADAS score in the recurrence group (verified in multicollinearity tests; Table 2).

For the patients with $\mathrm{MCl}$, a univariate logistic analysis with incidence or recurrence of missing events during the one-year follow-up period as the dependent variable showed significant differences in geriatric syndrome (Odds ratio (OR): 1.31, Confidence Interval (Cl): 1.03-1.67, p<0.03) and J-ZBI scores (OR: 1.06, $\mathrm{Cl}: 1.01-1.11, \mathrm{p}<0.02)$. In the multivariate logistic analysis, a significant difference remained only in geriatric syndrome $(0 \mathrm{R}: 1.38, \mathrm{Cl}: 1.05-1.83, \mathrm{p}<0.02)$. 
Table 2

Risk factors for the incidence of missing events due to wandering in patients with dementia

\begin{tabular}{|c|c|c|c|c|c|c|c|c|c|c|c|c|c|c|c|c|}
\hline & & \multirow{2}{*}{\multicolumn{4}{|c|}{$\begin{array}{l}\text { Univariate logistic analysis } \\
\text { Dependent variable: incidence } \\
\text { or recurrence during one year } \\
\text { follow up }\end{array}$}} & \multicolumn{11}{|c|}{ Multivariate logistic analysis } \\
\hline & & & & & & \multicolumn{4}{|c|}{$\begin{array}{l}\text { Dependent variable: incidence } \\
\text { or recurrence during one year } \\
\text { follow up }\end{array}$} & \multicolumn{4}{|c|}{$\begin{array}{l}\text { Dependent variable: incidence } \\
\text { during one year follow up }\end{array}$} & \multicolumn{3}{|c|}{$\begin{array}{l}\text { Dependent variable: } \\
\text { recurrence during one ye } \\
\text { follow up }\end{array}$} \\
\hline & & B & OR & $\mathrm{Cl}$ & $\mathrm{p}$ & B & OR & $\mathrm{Cl}$ & $\mathrm{p}$ & B & OR & $\mathrm{Cl}$ & $\mathrm{p}$ & B & OR & $\mathrm{Cl}$ \\
\hline \multirow[t]{9}{*}{$\begin{array}{l}\text { Medical } \\
\text { factors of } \\
\text { patients }\end{array}$} & $\begin{array}{l}\text { Mini-Mental } \\
\text { State } \\
\text { Examination }\end{array}$ & -0.14 & 0.87 & $\begin{array}{l}0.80- \\
0.95\end{array}$ & 0.01 & -0.13 & 0.88 & $\begin{array}{l}0.78- \\
0.99\end{array}$ & 0.04 & -0.13 & 0.88 & $\begin{array}{l}0.78- \\
0.99\end{array}$ & 0.04 & -0.10 & 0.90 & $\begin{array}{l}0.78- \\
1.00\end{array}$ \\
\hline & $\begin{array}{l}\text { Dementia } \\
\text { Behavior } \\
\text { Disturbance } \\
\text { Scale }\end{array}$ & 0.06 & 1.07 & $\begin{array}{l}1.03- \\
1.10\end{array}$ & $\begin{array}{l}\mathrm{p}< \\
0.001\end{array}$ & 0.04 & 1.04 & $\begin{array}{l}1.00- \\
1.09\end{array}$ & 0.06 & 0.03 & 1.04 & $\begin{array}{l}0.99- \\
1.08\end{array}$ & 0.12 & 0.04 & 1.04 & $\begin{array}{l}0.99- \\
1.10\end{array}$ \\
\hline & $\begin{array}{l}\text { Alzheimer's } \\
\text { Disease } \\
\text { Assessment } \\
\text { Scale }\end{array}$ & 0.10 & 1.10 & $\begin{array}{l}1.04- \\
1.17\end{array}$ & $\begin{array}{l}p< \\
0.001\end{array}$ & 0.05 & 1.05 & $\begin{array}{l}0.97- \\
1.14\end{array}$ & 0.23 & 0.05 & 1.05 & $\begin{array}{l}0.97- \\
1.13\end{array}$ & 0.23 & 1.21 & 1.13 & $\begin{array}{l}1.02- \\
1.25\end{array}$ \\
\hline & $\begin{array}{l}\text { Raven's } \\
\text { Colored } \\
\text { Progressive } \\
\text { Matrices }\end{array}$ & -0.09 & 0.92 & $\begin{array}{l}0.87- \\
0.97\end{array}$ & 0.01 & -0.05 & 0.95 & $\begin{array}{l}0.89- \\
1.02\end{array}$ & 0.15 & -0.04 & 0.96 & $\begin{array}{l}0.90- \\
1.02\end{array}$ & 0.21 & -0.03 & 0.97 & $\begin{array}{l}0.90- \\
1.10\end{array}$ \\
\hline & $\begin{array}{l}\text { Frontal } \\
\text { Assessment } \\
\text { Battery }\end{array}$ & -0.12 & 0.88 & $\begin{array}{l}0.80- \\
0.98\end{array}$ & 0.02 & 0.06 & 1.06 & $\begin{array}{l}0.91- \\
1.22\end{array}$ & 0.45 & 0.04 & 1.04 & $\begin{array}{l}0.91- \\
1.21\end{array}$ & 0.55 & 0.04 & 1.04 & $\begin{array}{l}0.86- \\
1.25\end{array}$ \\
\hline & $\begin{array}{l}\text { Geriatric } \\
\text { syndrome }\end{array}$ & 0.07 & 1.07 & $\begin{array}{l}0.98- \\
1.17\end{array}$ & 0.14 & & & & & & & & & & & \\
\hline & $\begin{array}{l}\text { Vitality } \\
\text { index }\end{array}$ & -0.12 & 0.88 & $\begin{array}{l}0.71- \\
1.10\end{array}$ & 0.26 & & & & & & & & & & & \\
\hline & $\begin{array}{l}\text { Geriatric } \\
\text { Depression } \\
\text { Scale }\end{array}$ & 0.04 & 1.04 & $\begin{array}{l}0.93^{-} \\
1.15\end{array}$ & 0.52 & & & & & & & & & & & \\
\hline & $\begin{array}{l}\text { Anti- } \\
\text { dementia } \\
\text { medicine }\end{array}$ & 0.28 & 1.32 & $\begin{array}{l}0.63- \\
2.76\end{array}$ & 0.46 & & & & & & & & & & & \\
\hline \multirow[t]{5}{*}{$\begin{array}{l}\text { Caregiver's } \\
\text { factors }\end{array}$} & $\begin{array}{l}\text { Caregiver's } \\
\text { Geriatric } \\
\text { Depression } \\
\text { Scale }\end{array}$ & 0.13 & 1.14 & $\begin{array}{l}1.03- \\
1.27\end{array}$ & 0.01 & 0.10 & 1.10 & $\begin{array}{l}0.96- \\
1.26\end{array}$ & 0.17 & 0.10 & 1.11 & $\begin{array}{l}0.97- \\
1.27\end{array}$ & 0.13 & 0.14 & 1.04 & $\begin{array}{l}0.98- \\
1.35\end{array}$ \\
\hline & $\begin{array}{l}\text { Japanese } \\
\text { version of } \\
\text { the Zarit } \\
\text { caregiver } \\
\text { burden } \\
\text { interview }\end{array}$ & 0.04 & 1.04 & $\begin{array}{l}1.02- \\
1.06\end{array}$ & $\begin{array}{l}p< \\
0.001\end{array}$ & 0.01 & 1.00 & $\begin{array}{l}0.97- \\
1.03\end{array}$ & 0.90 & 0.01 & 1.01 & $\begin{array}{l}0.98- \\
1.04\end{array}$ & 0.66 & 0.01 & 1.00 & $\begin{array}{l}0.96- \\
1.01\end{array}$ \\
\hline & $\begin{array}{l}\text { Providing } \\
\text { care every } \\
\text { day }\end{array}$ & 0.45 & 1.56 & $\begin{array}{l}0.70- \\
3.46\end{array}$ & 0.27 & & & & & & & & & & & \\
\hline & $\begin{array}{l}\text { Experience } \\
\text { of } \\
\text { caregiving } \\
\text { for a patient } \\
\text { with } \\
\text { dementia }\end{array}$ & 0.09 & 1.09 & $\begin{array}{l}0.50- \\
2.40\end{array}$ & 0.83 & & & & & & & & & & & \\
\hline & $\begin{array}{l}\text { Attended } \\
\text { seminar for } \\
\text { caregiving } \\
\text { for a patient } \\
\text { with } \\
\text { dementia }\end{array}$ & -0.11 & 0.90 & $\begin{array}{l}0.38- \\
2.09\end{array}$ & 0.80 & & & & & & & & & & & \\
\hline
\end{tabular}

Univariate logistic models were adjusted for age. Multivariate logistic models were adjusted for age, sex, years of education, and economic difficulty.

\section{Discussion}

Incidence rate and recurrence rate of missing events 
Incidence and recurrence rates differed between the two groups with dementia and $\mathrm{MCl}$. This result suggests that it is not appropriate to place all types of cognitive impairment in one category while performing the analysis.

These results are within the scope of those found in previous studies on the incidence rates of missing events in community-dwelling older adults. Most of those studies were cross-sectional. Studies on Alzheimer's disease by Rolland et al. [17], Klein et al. [11], and McShane et al. [18] found the prevalence of wandering to be $12.6 \%, 17.4 \%$, and $24.0 \%$, respectively.

Barrett et al. [2] conducted a two-year prospective longitudinal study on adults aged 60 years or older with mild dementia and found that $45.9 \%$ of participants demonstrated wandering. In a two- and half-year follow-up study by Pai et al. on those with Alzheimer's disease, the incidence rate was $33.3 \%$, and the recurrence rate was $40 \%$ [19].

However, this is the first cohort study to assess all the patients during a given period and further divided them at baseline based on whether or not they had a past missing event. We have also examined the recurrence and incidence of missing events. Thus, the results of the present study may be considered as highly reliable observational findings. The present study results suggest that people diagnosed with dementia require more careful observation to monitor the possibility of going missing and those with a missing incident require cautious attention.

\section{Risk factors associated with the incidence and recurrence of missing events}

Tests of the relationship between missing events during the one-year follow-up period and personal attributes, such as sex, age, years of education, living alone, or financial difficulty at baseline did not reveal any significant findings consistent with the findings of previous studies [4,20].

Although univariate logistic analysis showed that medical factors, such as MMSE, DBD, ADAS, RCPM, and FAB scores play a role, multivariate logistic analysis controlling for age, sex, years of education, and financial difficulty only showed significant effects from MMSE and DBD scores. When incidence and recurrence were examined separately, the only significant factors that remained were the MMSE score for incidence and ADAS score for recurrence. Comparing ADAS and MMSE, the former is a method for evaluating the therapeutic effect in Alzheimer's disease, whereas the latter is a comprehensive evaluation method for cognitive function. Therefore, recurrence of missing incidents may be more strongly influenced by the effectiveness of the treatment for dementia.

The MMSE score differed significantly between those who had a missing event during the follow-up period (mean 18.1, SD 4.8) and those who did not (mean 21.5, SD 4.4). So far, studies have found a higher likelihood of occurrence of a missing event among those with a mild or severe cognitive impairment than those with no cognitive impairment $[4,10,11]$. In the present study, participants with an MMSE score of 15 to 20 went missing most frequently. In particular, after one year of follow-up, the MMSE score distribution for those who had no missing events, those who had their first missing event, and those who had a recurrent missing event separately showed that those scoring $\leq 20$ points required careful observation and those scoring $\leq 15$ points were at a high risk of a recurrence.

Findings have also shown a higher likelihood of missing events among those with DBD [21] or a high score on the ADAS [22].

We also analyzed the relationships with variables that are considered risk factors for cognitive decline and dementia (lifestyle risk factors, such as current smoking [23], alcohol consumption [24], physical inactivity [25], and sleep disturbances [26]), but did not observe any associations between these variables and missing events. Studies have found a relationship between depression and wandering [11], but we did not find a significant association between them in the present study.

Regarding family caregivers, the univariate logistic analysis showed that a greater tendency towards wandering was observed as the family's burden increased [22]. Family caregivers of patients with a history of missing incidents had a higher sense of burden than caregivers of patients with no history of missing incidents.

For patients with $\mathrm{MCl}$, in addition to the MMSE and DBD scores, J-ZBI (OR:1.03, $\mathrm{p}<0.05)$ score also remained as a significant factor, suggesting that support is needed for family care of patients with dementia from an early stage.

Missing incidents can potentially occur with anyone whose cognitive impairment progresses, and appropriate care is required. Care by family caregivers of persons with dementia can reduce specific dementia-related behaviors and the frequency and seriousness of psychological symptoms [27]. On the other hand, family caregivers' physical and mental health is a predictive factor of dementia-related missing events [28]. Although the severity of dementia may be one of the significant risk factor responsible for missing events, the relationship between the person with dementia and their family caregivers also has a strong impact. Missing events are the most burdensome behavior for family caregivers [17] and lead many caregivers to lock the doors [18].

While effective management and technological interventions to reduce missing events can help lessen the burden on family caregivers [29], only about 20\% of the participants surveyed in our study had participated in a seminar or other event providing information on dementia. A social environment that can support family caregivers needs to be developed to reduce the sense of burden on family caregivers who are caring for persons with dementia and the number of missing events due to wandering.

A significant aspect of the present study is that it was a prospective cohort study examining all patients who visited the National Center for Geriatrics and Gerontology during a certain period. In addition, patients with dementia and patients with $\mathrm{MCl}$ were analyzed separately to determine the incidence and recurrence rates and the risk factors based on the extent and stage of cognitive function decline. This had not been done in previous studies, and it offers new insights.

\section{Conclusions}


So far, not enough studies have thoroughly examined the extent to which dementia-related wandering and missing incidents occur in the community. A significant aspect of the present study is that it was a prospective cohort study examining all patients during a certain period. Prevention of missing events due to wandering requires focused attention on changes in the MMSE, DBD, ADAS scores, and the development of a social environment to support family caregivers.

\section{Abbreviations}

MCI: ; BMI: body mass index; BI: Barthel index; MMSE: Mini-Mental State Examination; DBD: Dementia Behavior Disturbance Scale; ADAS: Alzheimer's Disease Assessment Scale; RCPM: Raven's Colored Progressive Matrices; FAB: Frontal Assessment Battery; GDS: Geriatric Depression Scale; J-ZBI: the Japanese version of the Zarit caregiver burden interview

\section{Limitation}

This study has some limitations. One is that the follow-up period was only one year. A second limitation is that the sample size of patients with $\mathrm{MCl}$ was small, and only seven had a missing event during the follow-up period, which was insufficient for statistical tests. A third limitation of this study is that we did not collect clinical data as our endpoint, and thus, could not include clinical information that has a causal association with missing events in our analysis

\section{Declarations}

\section{Ethics approval and consent to participate}

This study adhered to the tenets of the Declaration of Helsinki and the ethical standards declared in ethical guidelines for medical research involving human subjects. The Ethics and Conflicts approved the study protocol of the Interest Committee of the National Center for Geriatrics and Gerontology (No. 977-2).

\section{Consent for publication}

Not applicable

\section{Availability of data and materials}

The datasets analysed during the current study are available from the corresponding author on reasonable request. All data analysed during this study are included in this published article.

\section{Competing interests}

The authors declare that they have no competing interests $\Downarrow$

\section{Funding}

This research was funded by the Health Labour Sciences Research Grant (201816001B).

\section{Authors' contributions}

Sakurai T. and Suzuki T. contributed to research design and protocol development; Miura K. collected and verified all data; Jeong S. and Miura K. analyzed and interpreted results; Jeong S., Suzuki T., Miura K., and Sakurai T. drafted the report and approved the final version of the article.

\section{Acknowledgements}

Not applicable

\section{References}

1. WHO. Dementia; 2019. https://www.who.int/news-room/fact-sheets/detail/dementia. Accessed 25 June 2021.

2. B. Barrett, T. Bulat, S.K. Schultz, S.L. Luther. Factors associated with wandering behaviors in veterans with mild dementia: a prospective longitudinal community-based study. Am J Alzheimers Dis Other Demen 2018;33:100-111.

3. D.L. Algase, D.H. Moore, C. Vandeweerd, D.J. Gavin-Dreschnack. Mapping the maze of terms and definitions in dementia-related wandering. Aging Ment Health 2007;11:686-698.

4. T. Hope, J. Keene, R.H. McShane, C.G. Fairburn, K. Gedling, R. Jacoby. Wandering in dementia: a longitudinal study. Int Psychogeriatr 2001;13:137-147.

5. A.A. Adekoya, L. Guse. Wandering behavior from the perspectives of older adults with mild to moderate dementia in long-term care. Res Gerontol Nurs 2019;12:239-247.

6. K. Kikuchi, M. ljuin, S. Awata, T. Suzuki. Exploratory research on outcomes for individuals missing through dementia wandering in Japan. Geriatr Gerontol Int 2019;19:902-906.

7. T. Saito, C. Murata, S. Jeong, Y. Inoue, T. Suzuki. Prevention of accidental deaths among people with dementia missing in the community in Japan. Geriatr Gerontol Int 2018;18:1301-1302. 
8. S. Jeong, Y. Inoue, T. Saito, C. Murata, T. Suzuki. The characteristics of elderly who wandered and got lost due to dementia and the municipalities' measures: all municipalities of a prefecture (54 municipalities) in 2014-2015. J Jpn Soc Demen Care 2018;17:457-463.

9. C.K. Lai, D.G. Arthur. Wandering behaviour in people with dementia. J Adv Nurs 2003;44:173-182.

10. H. Lövheim, P.O. Sandman, S. Karlsson, Y. Gustafson. Behavioral and psychological symptoms of dementia in relation to level of cognitive impairment. Int Psychogeriatr 2008;20:777-789.

11. D.A. Klein, M. Steinberg, E. Galik, C. Steele, J.M. Sheppard, A. Warren, A. Rosenblatt, C.G. Lyketsos. Wandering behaviour in community-residing persons with dementia. Int J Geriatr Psychiatry 1999;14:272-279.

12. P. Dawson, D.W. Reid. Behavioral dimensions of patients at risk of wandering. Gerontologist 1987;27:104-107.

13. A.L. Nelson. Evidence-Based Protocols for Managing Wandering Behaviors. Springer Publishing Company New York, NY; 2007.

14. A.M. Houston, L.M. Brown, M.A. Rowe, S.D. Barnett. The informal caregivers' perception of wandering. Am J Alzheimers Dis Other Demen 2011;26:616622.

15. M. Rowe, A. Houston, V. Molinari, T. Bulat, M.E. Bowen, H. Spring, S. Mutolo, B. McKenzie. The concept of missing incidents in persons with dementia. Healthcare (Basel) 2015;3:1121-1132.

16. Y. Arai, K. Kudo, T. Hosokawa, M. Washio, H. Miura, S. Hisamichi. Reliability and validity of the Japanese version of the Zarit Caregiver Burden Interview. Psychiatry Clin Neurosci 1997;51:281-287.

17. Y. Rolland, S. Gillette-Guyonnet, F. Nourhashémi, S. Andrieu, C. Cantet, P. Payoux, P.J. Ousset, B. Vellas. Wandering and Alzheimer's type disease. Descriptive study. REAL.FR research program on Alzheimer's disease and management. Rev Med Interne 2003;24 Suppl. 3:333s-338s.

18. R. McShane, K. Gedling, J. Keene, C. Fairburn, R. Jacoby, T. Hope. Getting lost in dementia: a longitudinal study of a behavioral symptom. Int Psychogeriatr 1998;10:253-260.

19. M.C. Pai, C.C. Lee. The incidence and recurrence of getting lost in community-dwelling people with Alzheimer's disease: a two and a half-year follow-up. PLOS ONE 2016;11:e0155480.

20. N. Ali, S.L. Luther, L. Volicer, D. Algase, E. Beattie, L.M. Brown, V. Molinari, H. Moore, I. Joseph. Risk assessment of wandering behavior in mild dementia. Int J Geriatr Psychiatry 2016;31:367-374.

21. N. O'Rourke, M. Bédard, Y.G. Bachner. Measurement and analysis of behavioural disturbance among community-dwelling and institutionalized persons with dementia. Aging Ment Health 2007;11:256-265.

22. Y. Rolland, S. Andrieu, C. Cantet, J.E. Morley, D. Thomas, F. Nourhashemi, B. Vellas. Wandering behavior and Alzheimer disease. The REAL.FR prospective study. Alzheimer Dis Assoc Disord 2007;21:31-38.

23. B.L. Plassman, J.W. Williams, Jr., J.R. Burke, T. Holsinger, S. Benjamin. Systematic review: factors associated with risk for and possible prevention of cognitive decline in later life. Ann Intern Med 2010;153:182-193.

24. E.J. Neafsey, M.A. Collins. Moderate alcohol consumption and cognitive risk. Neuropsychiatr Dis Treat 2011;7:465-484.

25. S.J. Blondell, R. Hammersley-Mather, J.L. Veerman. Does physical activity prevent cognitive decline and dementia?: a systematic review and metaanalysis of longitudinal studies. BMC Public Health 2014;14:510.

26. O. Potvin, D. Lorrain, H. Forget, M. Dubé, S. Grenier, M. Préville, C. Hudon. Sleep quality and 1-year incident cognitive impairment in community-dwelling older adults. Sleep 2012;35:491-499.

27. H. Brodaty, C. Arasaratnam, Meta-analysis of nonpharmacological interventions for neuropsychiatric symptoms of dementia. Am J Psychiatry 2012;169:946-953.

28. L.M. Peng, Y.C. Chiu, J. Liang, T.H. Chang. Risky wandering behaviors of persons with dementia predict family caregivers' health outcomes. Aging Ment Health 2018;22:1650-1657.

29. N.A. Neubauer, N. Lapierre, A. Ríos-Rincón, A. Miguel-Cruz, J. Rousseau, L. Liu. What do we know about technologies for dementia-related wandering? A scoping review: Examen de la portee: Que savons-nous a propos des technologies de gestion de l'errance liee a la demence? Can $\mathrm{J}$ Occup Ther 2018;85:196-208.

\section{Figures}



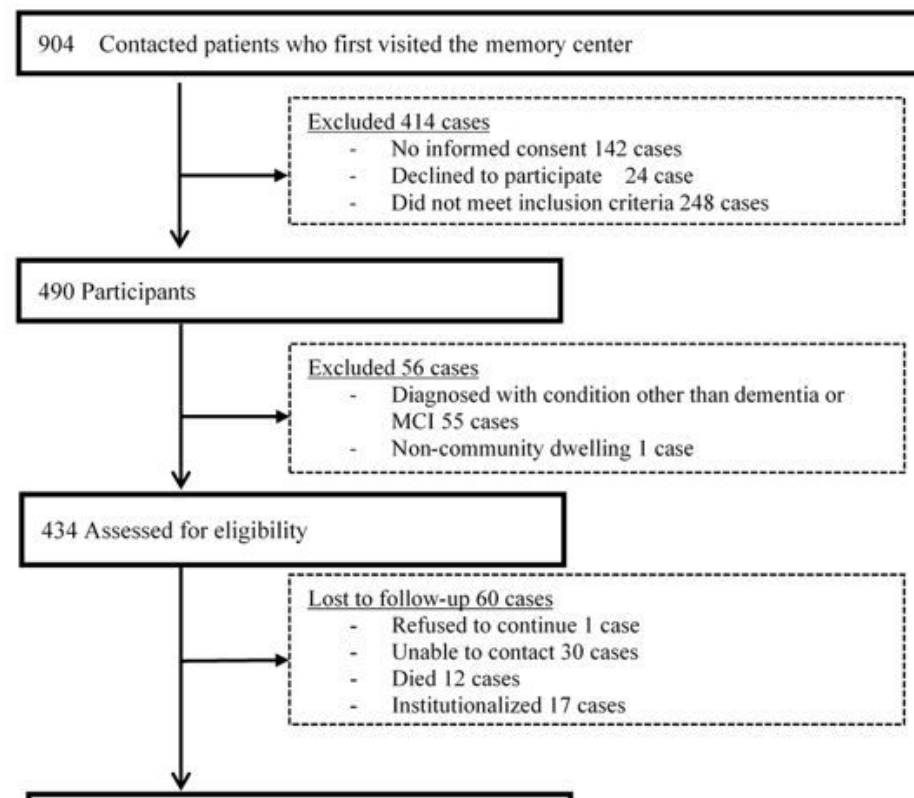

374 Analyzed

Figure 1

Study participants

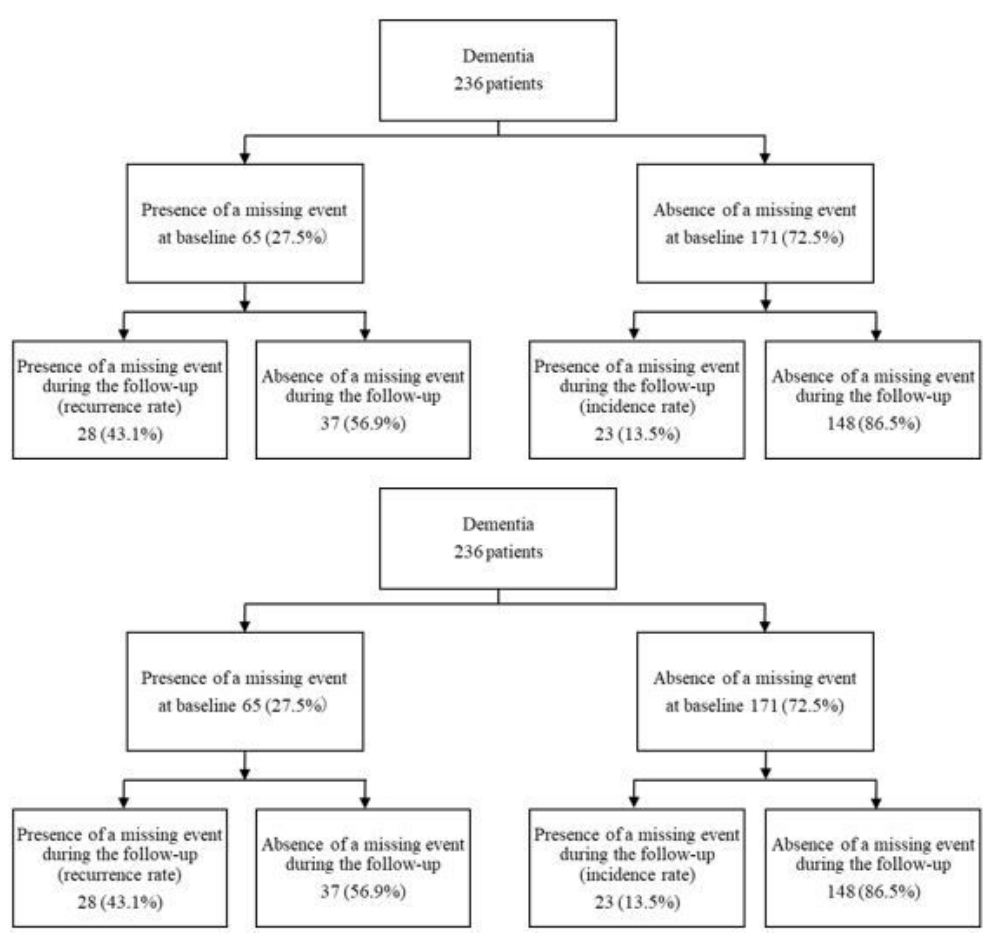

Figure 2

Incidence rate and recurrence rate of missing events due to wandering 